\title{
Classroom discipline in Australia
}

\section{The latest TALIS report shows the percentage of sampled lower secondary teachers* who "agreed" and "strongly agreed" with the following statements}
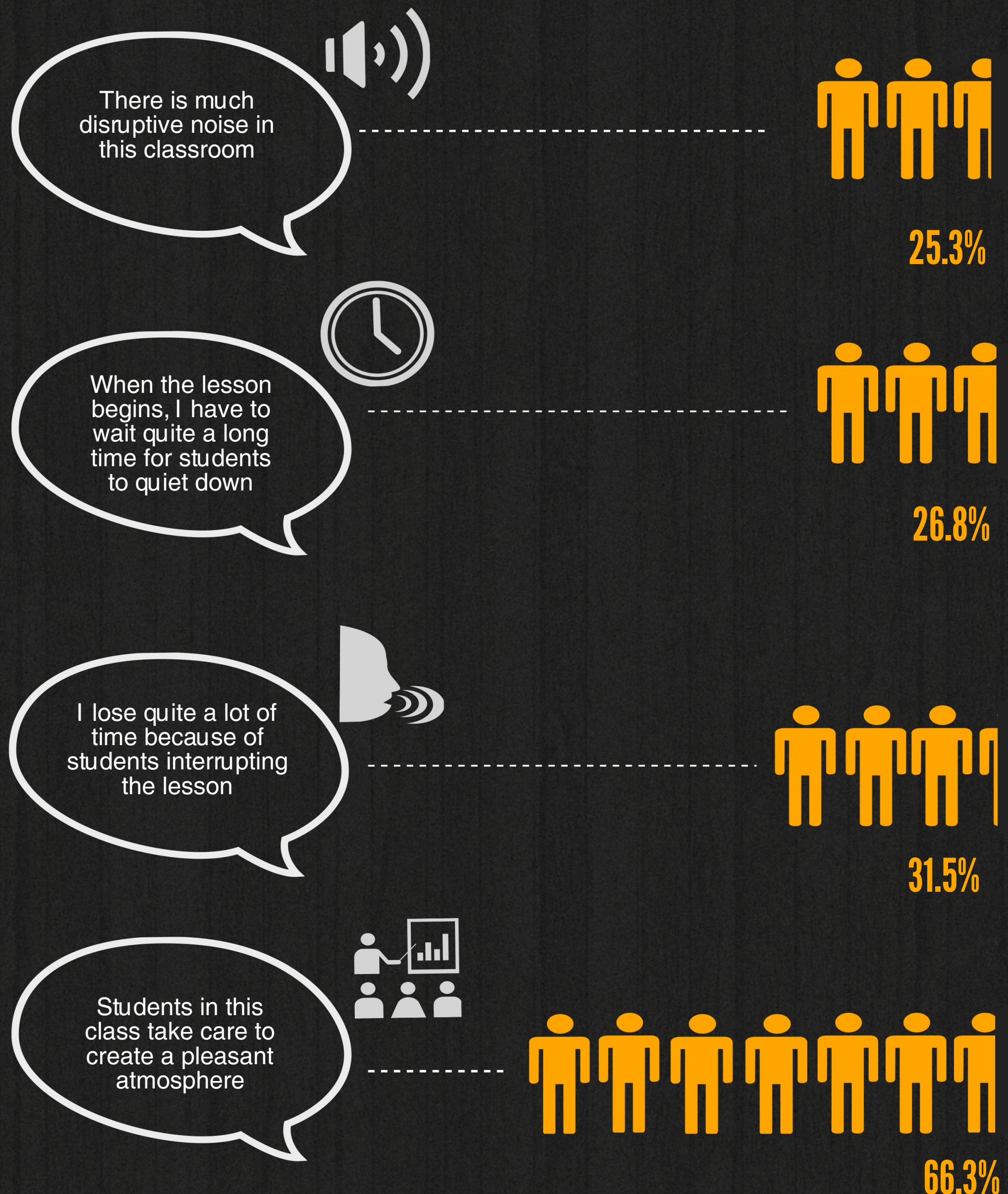

*This data is reported by a sample of teachers, who each refer to a randomly chosen class that they currently teach. 